\title{
Tecnologia Social de Mobilização para Arranjos Produtivos Locais: uma proposta de aplicabilidade
}

\section{Social Technology to Mobilize Local Productive Arrangements: a proposal for applicability}

\author{
Ana Sílvia Rocha Ipiranga ${ }^{1}$ \\ Mônica Alves Amorim² \\ Maria Vilma Coelho Moreira Faria ${ }^{3}$
}

\begin{abstract}
Resumo
Apesar do crescente interesse que a abordagem de Arranjos e Sistemas Produtivos Locais vem despertando no meio acadêmico e instituições públicas e privadas brasileiras, pouco se tem inovado acerca das formas de mobilização coletiva destas aglomerações produtivas territoriais, permanecendo as discussões nas áreas tradicionais de desenvolvimento das micro, pequenas e médias empresas. Este ensaio apresenta uma proposta de aplicação de uma Tecnologia Social de Mobilização dos atores/agentes de um arranjo produtivo local, objetivando o seu desenvolvimento, através do fortalecimento das relações existentes entre seus diversos atores/agentes localizados no território. Espera-se, através da exposição de uma possível aplicabilidade desta Tecnologia Social, gerar um debate sobre formas criativas de mobilização desses arranjos organizacionais, que privilegiem aspectos intangiveis, não obstante serem de fundamental importância, tais como: capital social, práticas cooperativas e governança.
\end{abstract}

Palavras-chave: Arranjos Produtivos Locais, Capital Social, Governança.

\begin{abstract}
Despite the growing interest on local productive systems revealed by both academia and public or private agencies, discussions about collective strategies to articulate them remain focusing on traditional aspects of small firms, lacking innovation and context-specific approaches. This essay proposes the use of a Social Technology framework to mobilize actors operating in local productive systems of small firms, aimed at strengthening relationships and promoting development. With this contribution, authors hope to stimulate a discussion about innovative ways to support collective action, emphasizing aspects such as social capital, cooperative practices and governance, all of which, though intangible, are crucial to local development.
\end{abstract}

Key-words: Local Productive Systems, Social Capital, Governance

\footnotetext{
${ }^{1}$ Mestrado Acadêmico em Administração. Coordenadora do Laboratório Tecnologias Digitais e Pesquisa Qualitativa Universidade Estadual do Ceará - Endereço: Av. Paranjana, 1700, Campus do Itaperi - Fortaleza-CE - Brasil. CEP.: 60740-000. E-mail: anasilviaipi@uol.com.br.

2 Mestre em Economia. Universidade Federal do Ceará. Endereço: Rua Flávio Marcílio - Dunas - Fortaleza/CE - Brasil -CEP:6000000. E-mail: mamorim@worlbank.org

${ }^{3}$ Doutora em Sociologia. Professora da Universidade de Fortaleza-UNIFOR. Endereço: R. Paulo Faustino, 103 - Luciano Cavalcante - Fortaleza/CE - Brasil - CEP: 60813530 - E-mail: vmoreira@unifor.br.

Artigo recebido em julho de 2006 e aceito para publicação em setembro de 2006
} 


\section{Introdução}

Nas últimas décadas, diversas vertentes teóricas têm surgido acerca dos modelos de desenvolvimento econômico e social que têm sido praticados em várias regiões do mundo. Dentre elas, encontram-se análises relativas aos distritos industriais, entorno inovador, clusters e arranjos e sistemas produtivos e locais. Essas abordagens enfatizam o papel das aglomerações de empresas especializadas em produtos ou serviços, com ênfase numa área geográfica delimitada.

Numerosos estudos têm, também, ressaltado o importante papel das aglomerações territoriais de micro, pequenas e médias empresas (MPMEs) para o desenvolvimento regional e mobilização das economias locais. De fato, vários países têm reconhecido o potencial das MPMEs para gerar trabalho e riquezas e mobilizar a economia, contribuindo para a melhoria da distribuição de renda, compensando, assim, os desequilíbrios regionais. Entre várias experiências em diversos países, os distritos industriais da chamada "Terceira Itália" exemplificam uma experiência de sucesso de aglomerações territoriais de MPMEs, assim como os clusters nos Estados Unidos, onde se destaca o Vale do Silício, as redes de empresas no Japão, Coréia e Taiwan, e os sistemas produtivos locais na França, Alemanha e no Reino Unido (SAXENIAN, 1994; PORTER, 1998; BRUSCO, 1990).

No Brasil, as micro, pequenas e médias empresas exercem importância à medida que $98 \%$ das firmas existentes no país são consideradas micro, pequenas ou médias. Essas empregam $60 \%$ da população economicamente ativa e contribuem para a geração de $21 \%$ do Produto Interno Bruto brasileiro (MINISTÉRIO DA CIÊNCIA E TECNOLOGIA, 2001).

Apesar de sua importância histórica, é reconhecido que as MPMEs, no Brasil, não têm recebido a atenção apropriada dos gestores públicos, devido à visão errônea de que as empresas pequenas são formas ineficientes de organização, que, mesmo contribuindo para gerar renda para a população, não possuem eficiência e competitividade para sobreviver numa economia global.

As MPMEs são, então, lembradas quase como uma panacéia para solucionar as perdas e outros constrangimentos sociais que o desemprego provoca. Nesse contexto, os programas voltados para a promoção desse segmento se revestem mais de um caráter social, em contraposição à motivação econômica. Recorre-se às MPMEs como uma espécie de colchão de amortecimentos dos choques macro-econômicos, ao invés de se considerá-las agentes eficientes de produção, capazes de acelerar o crescimento, melhorar a distribuição de renda, e lograr ganhos de competitividade para a economia nacional (TENDLER, 2001).

Esse tem sido o viés das políticas recentes de apoio às MPMEs, não só no Brasil, mas em grande parte do mundo em desenvolvimento. Como uma evidência desse fato, aponta-se que, até a primeira metade da década de 90, um dos principais programas nacionais de apoio às MPMEs encontrava-se abrigado em um órgão de promoção social, a extinta Legião Brasileira de Assistência - LBA, vinculada ao Ministério da Ação Social.

A fundamentação de que MPME constitui uma estratégia de política social decorre do entendimento equivocado de que essas são formas ineficientes de produção, e assim constituem uma "opção de segunda classe" para uma real estratégia de crescimento econômico. Entretanto, ainda segundo essa visão, tais estruturas de produção não devem ser inteiramente abandonadas à sua própria sorte devido aos impactos positivos que produzem em favor da estabilidade política dos governos (status quo) tais como: ocupar e gerar renda para parte significativa da população, que de outra forma estaria desocupada e marginalizada da atividade econômica; aliviar as taxas de desemprego; iniciar os indivíduos nos negócios, enquanto "melhores" opções não surgem no horizonte.

Esse entendimento constitui um equívoco, desperdiçando oportunidades de crescimento, sobretudo se considera que um modelo de desenvolvimento baseado em MPMEs permite que uma parcela maior de indivíduos passe a integrar a classe de proprietários, torne-se micro e pequenos empresários e assim se aproprie dos resultados da produção. ${ }^{1}$ Dessa forma, a expansão da produção, associada à ampliação da classe de pequenos empresários, 
constitui uma forma de crescimento economicamente mais justa e socialmente mais desejável sem, contudo, deixar de ser eficiente.

A despeito desse enfoque pouco otimista com o qual alguns países encaram as MPMEs, a realidade tem sido diferente em diversos outros que conseguiram alcançar, nas duas últimas décadas, taxas de crescimento bem apreciáveis, como, por exemplo, a Itália e Taiwan. ${ }^{2}$ Nesses e em outros locais, as MPMEs constituem parte relevante do aparelho produtivo nacional, merecendo dos governos um tratamento correspondente a seu papel na economia. Além disso, nesses países, as políticas de apoio ao segmento têm enfoque de produção, vinculam-se às estratégias de crescimento econômico, de aumento da renda nacional, de ganhos de competitividade, de aumento das exportações, objetivos esses essencialmente econômicos, em contraposição à mera proteção social de um contingente da parcela menos aquinhoado da população.

As experiências das últimas décadas têm demonstrado claramente que as MPMEs podem ter um papel crucial no desenvolvimento de um país. Portanto, torna-se importante compreender a gênese e a dinâmica do seu funcionamento, sem compará-las com a organização das grandes empresas. Quando as MPMEs se organizam como unidades de produção isoladas, reproduzindo a forma de funcionamento de grandes empresas, as primeiras não têm como superar uma das principais dificuldades que lhes perseguem: a incapacidade de gerar economias de escala. Como essas economias são tipicamente associadas a grandes volumes de produção, algo quase sempre próprio das grandes empresas, as MPMEs ficam relegadas à condição de unidades de produção ineficientes, pois seus custos tendem a ser maiores do que os das empresas de maior porte, o que reforça a idéia de que as MPMEs parecem não ter as credencias para se colocar como agentes preferenciais do processo de desenvolvimento econômico.

De fato, as MPMEs são afetadas por diversos problemas, tais como escassez de financiamento, baixo nível de qualificação da sua mão-de-obra, dificuldade de acesso a novas tecnologias, dentre outros. Esses desafios são de difícil solução, mormente se encarados pelas MPMEs de forma isolada. Portanto, essas empresas devem encontrar uma forma de operação e organização apropriada às suas condições de produção referentes a escala, escopo e disponibilidade de fatores de produção.

A necessidade de buscar eficiência e competitividade força as MPMEs a desenvolverem um modelo próprio de organização, baseado em fatores como aglomeração, proximidade, especialização e complementaridade. As aglomerações de MPMEs podem encorajar cooperação, aprendizagem e troca de informações entre as unidades produtivas tornando-as mais eficientes e competitivas (AMORIM, 1998).

Este trabalho, dentre as abordagens citadas acima, privilegiou aquela denominada de "arranjos produtivos locais - APL", por entender que a mesma é um enfoque mais apropriado para a análise de aglomerações produtivas, territoriais, sobretudo de MPMEs localizadas em regiões menos desenvolvidas e, por inserir, em sua análise, uma rede de agentes que interagem de forma específica no APL, tais como agências de fomento ao crédito, instituições de pesquisa e qualificação de mão-de-obra, associações de classe, organizações do terceiro setor, possibilitando uma maior interação entre diversos atores/agentes relevantes para o desenvolvimento do território.

Os arranjos produtivos locais (APLs) podem ser definidos como sendo "aglomerações territoriais de agentes econômicos, políticos e sociais, com foco em um conjunto específico de atividades econômicas e que apresentam vínculos e interdependência”. Já os, assim, chamados sistemas produtivos locais (SPLs) que representam formas mais sistêmicas e com maior nível de interdependência entre os agentes, são definidos como "sistemas produtivos cuja interdependência, articulação e vínculos consistentes resultam em interação, cooperação e aprendizagem, possibilitando inovações de produtos, processos e formatos organizacionais e gerando mais competitividade empresarial e capacitação social" (ALBAGLI; BRITO, 2002:3). Desta forma, os arranjos e sistemas produtivos locais, ao incluírem os atores externos à atividade produtiva, oferecem a possibilidade de uma compreensão mais aprofundada da dinâmica do entorno econômico, social e político, do qual fazem parte. 
Neste trabalho, entretanto, optou-se por privilegiar a abordagem de arranjos produtivos e não, sistemas, em razão da primeira refletir mais a situação das aglomerações produtivas a serem estudadas, que ainda se encontram em estágio de organização incipiente, sem uma articulação mais consistente entre seus membros e outras instituições presentes no território. A par da, relativamente, rápida disseminação da abordagem de APL no Brasil, muitos dos estudos existentes se restringem mais a descrição e/ou diagnóstico dos arranjos enfocados e, menos a propostas e formulação de estratégias para o seu desenvolvimento.

Tendo como objetivo preencher uma lacuna nos estudos relacionados à temática de aglomerações de empresas, sobretudo nas discussões sobre os "arranjos produtivos locais" (APLs), este ensaio propõe uma Tecnologia Social - TS (SECRETARIA EXECUTIVA DA REDE DE TECNOLOGIA SOCIAL, 2004) de Mobilização dos Arranjos Produtivos Locais, cuja elaboração tem, por base, o conceito de capital social (PUTNAM, 1993; ALBAGLI; MACIEL, 2003; BERETTA; CURINI, 2003), articulando, entre os três "tipos ideais" de governança,propostos por Messner e Meyer-Stamer (2000), o pressuposto teórico de "governança em rede". Em um segundo momento, apresenta-se um exemplo de aplicação dessa Tecnologia Social de Mobilização em dois casos de APLs, selecionados no estado do Ceará.

O suporte metodológico utilizado baseou-se na abordagem de Bruyne et al.(1991) que prevê a interação dinâmica entre os quatro aspectos de produção da prática científica, a saber: o pólo epistemológico onde são explicitados o objeto e a problemática da pesquisa; o pólo teórico, que guia a construção dos conceitos, propondo as regras de interpretação dos fatos; o pólo morfológico, que enuncia as regras de estruturação da formação do objeto de estudos através de modelos, tipologias e "tipos-ideais"; e por fim, o pólo técnico, que controla a coleta de dados e o confronto com a teoria que os suscitou. A partir desses aspectos metodológicos acima explicitados, as questões centrais que norteiam este estudo são as seguintes: Que instrumentos podem ser criados para estimular a interação, cooperação e coordenação dos diversos atores envolvidos em um APL? De que forma esses instrumentos poderiam ser aplicados à realidade dos casos estudados?

Para respondê-las apresenta-se, na primeira sessão desde trabalho, uma discussão histórica e teórica sobre as diversas tipologias de aglomerações de micros, pequenas e médias empresas, colocando em foco a discussão sobre o capital social e a governança, enquanto categorias estratégicas para a sustentabilidade e competitividade desse tipo de arranjos organizacionais. Em seguida aprofunda-se sobre a questão da promoção da governança, explicitando-se os três "tipos ideais" de governança proposto por Messner e Meyer-Stamer (2000) e o modelo, segundo Humphrey e Schmitz (2000), das três categorias, a nível local e global, de governança. Com base no conceito de capital social e no pressuposto teórico da "governança em rede" e, considerando as regras metodológicas do pólo morfológico proposto por Bruyne et al (1991), na terceira sessão, propõe-se uma Tecnologia Social de Mobilização dos Arranjos Produtivos Locais (APLs). Considerando-se que as Tecnologias Sociais (TS) são vistas como um desafio igualmente teórico e prático, na quarta sessão apresentase uma possível aplicação da Tecnologia Social anteriormente estruturada em dois arranjos produtivos locais (APLs), localizados no Ceará. Os setores de atuação dos dois casos sob estudo são bem diversificados e com forte tradição local, quais sejam: artesanato em crochê e redes de dormir. Para esta aplicação foi realizada uma pesquisa exploratória com visitas in loco nos dois APLs selecionados, incluindo os procedimentos da observação participante e de entrevistas com 'informantes-chave' das diversas instituições públicas e privadas e MPMEs localizadas nos territórios dos arranjos, bem como levantamento de dados secundários através da análise documental. Ao final, o ensaio apresenta uma reflexão acerca da aplicabilidade do modelo proposto.

\section{Tipologia de Aglomerações de Micro, Pequenas e Médias Empresas}

A nova economia global tem, como características predominantes, a formação de blocos regionais, através da diminuição de barreiras entre os países membros, o uso da informação e do conhecimento de forma mais intensa, o crescimento do setor de serviços, o downsizing das organizações de grande porte, e fusões e alianças entre as empresas. Esses fatores, além de reduzir as possibilidades de empregos formais, têm estimulado a criação de pequenos empreendimentos, sobretudo, na terceirização para grandes empresas como uma forma de sobrevivência no mercado (LALKAKA, 1997). 
A mudança dos paradigmas organizacionais, resultado da nova economia global, tem proporcionado o surgimento do modelo da produção flexível, que encontra, nas MPMEs, uma dinâmica de funcionamento eficaz, principalmente quando funcionam de forma coletiva. As MPMEs têm, a partir da reestruturação produtiva dos anos 70, começado a incorporar tecnologia de ponta nos processos produtivos e a modificar estruturas organizacionais internas. Elas têm, também, começado a buscar vínculos com o entorno sócioeconômico, constituindo uma forma de reestruturação industrial capaz de competir em alguns setores com grandes empresas. Essas transformações têm ocorrido, sobretudo, no âmbito das inovações tecnológicas das indústrias eletrônicas, robótica e da informática. Assim, cria-se um novo debate acerca da importância das MPMEs, diante do seu bom desempenho na criação de empregos, mesmo em períodos de recessão (BRUSCO, 1990; CASTELLS, 1986; PIORE; SABEL, 1984; TENDER; AMORIM, 1996).

O processo de globalização da economia tem ocasionado um redesenho das forças produtivas com ênfase na flexibilidade, inovação e qualidade. A expansão de novas formas flexíveis de organização da produção aponta para a falência do modelo ' fordista', trazendo consequiências importantes no âmbito econômico, social, organizacional e tecnológico. A chamada "especialização flexível" destaca-se, assim, como um novo modelo de organização industrial, com exemplos 'exitosos' na Terceira Itália, Alemanha, França, que tiveram, como base, a expansão de micro, pequenas e médias empresas, cuja adaptabilidade a flutuações de demanda e cujo dinamismo inovador tornaram-nas organizações importantes neste novo modelo industrial que tem se delineado nas últimas décadas (BAPTISTA, 2003).

O conceito de "especialização flexível" nos reporta para outro conceito de aglomerações industriais elaborado por Alfred Marshall (1996), o 'distrito industrial' que engloba aspectos, tais como: firmas especializadas, 'territorialidade', mercado de trabalho e cooperação. O ressurgimento da idéia do 'distrito marshalliano' ocorre no recente período de reestruturação produtiva, decorrente do esgotamento dos modelos 'taylorista/fordista', que ocasionaram, além do aumento do desemprego formal, a precariedade do trabalho e o crescimento das economias informais. Em contrapartida, o tipo de distrito industrial 'marshalliano' acena para a possibilidade de construção de um lócus de cooperação, baseado na confiança e em aspectos sócio-culturais, formado pelas redes de interação entre os agentes/atores localizados em um território delimitado.

Apesar do forte otimismo que causou, frente à desestruturação de formas clássicas de organização da produção, o modelo de distrito industrial também tem apresentado sinais de esgotamento. Como ressaltam Schmitz e Nadvi (1999) e Le Borgne (1991), o distrito industrial italiano, exemplo, na literatura, do modelo 'marshalliano', começa, sobretudo nos anos 90, a apresentar mudanças na sua dinâmica de funcionamento. A cooperação cede lugar para formas de contratualidade entre firmas, a constituição de firmas líderes, a especialização em produtos de baixa qualidade e o emprego de mão-de-obra pouco qualificada (AMARAL, 1999).

Há diversas abordagens que analisam aglomerações de empresas. Dentre elas, destacam-se as seguintes: a nova geografia econômica, tendo Krugman (1993) como seu principal expoente, a economia de empresas, na qual se destaca Porter (1998), a abordagem de clusters, com A. Scott (1988), a economia de inovação, com a contribuição destacada de Audrestch (1998), e a abordagem de pequenas empresas, distritos industriais, com destaque para Brusco (1990), Pyke, Becattini e Sengenberger (1992) e Schmitz (1994).

Todas essas vertentes analíticas utilizam, de forma intrínseca, conceitos da abordagem de sistema produtivo local, que já tem sido usada, de forma mais estruturada, em países desenvolvidos, e, de maneira mais incipiente, em países em desenvolvimento, no que se refere à estratégia de desenvolvimento regional e local.

A estratégia de cluster segue uma tendência 'porteriana', situa-se na fronteira entre a literatura de organização industrial e desenvolvimento regional e demonstra que a análise setorial não consegue captar a complexidade dos fenômenos que envolvem a dinâmica industrial. No entanto, a análise de clusters procura captar os elementos estruturais e sistêmicos da aglomeração, enfatizando a rivalidade entre as firmas e os fatores da sua dinâmica interna que afetam a competitividade dos agentes. Assim, a análise de clusters de empresas prioriza o estudo da sua estrutura, investigando-se, por exemplo, o tamanho das organizações, as articulações entre essas, 
os padrões de especialização e concorrência e as vantagens competitivas que podem ser criadas a partir da estruturação dessa modalidade de aglomeração produtiva.

Além das abordagens, acima, os estudos de Economia Regional enfatizam prioritariamente aspectos relativos aos 'fatores locacionais' que influenciam a implantação de uma indústria em determinada área geográfica, e seus desdobramentos na reprodução e transformação de regiões geo-econômicas específicas (BRITTO; ALBUQUERQUE, 2003). Esses enfoques apresentam alguns pontos confluentes e complementares, pois enfatizam a proximidade geográfica dos agentes produtivos e a relevância do contexto social e institucional como fatores importantes na consolidação dessas aglomerações. Contudo, a abordagem de cluster se aproxima mais da grande produção flexível do que da pequena, diferenciando-se tanto do modo 'fordista' de produção, baseado na grande empresa de produção em massa, como também, da visão do distrito industrial 'marshalliano' da pequena produção flexível. Além de enfatizar mais a concorrência do que a cooperação entre os membros do cluster, essa abordagem também atribui relevância à formação de uma empresa-chave ou empresas-chave numa determinada região. As empresas chamadas 'âncoras' estimulam, sem dúvida, o desenvolvimento da região, através da mobilização de agentes produtivos localizados no mesmo território, porém o crescimento mais homogêneo dos agentes produtores passa a ser secundário.

Diante da diversidade de vertentes teóricas acerca do desempenho competitivo das empresas, tem-se chegado a uma convergência das percepções de que o foco de análise não deve ser centrado apenas na empresa individual, mas, sobretudo, nas relações entre as firmas e entre estas e as instituições que interagem com elas num determinado espaço geográfico. Este novo foco tem possibilitado a reorientação de formas de intervenção do poder público na promoção da política industrial e tecnológica. Portanto, a abordagem de arranjos e sistemas produtivos locais tem a proposta de elaborar um modelo que englobe categorias tradicionais nas análises de aglomerações, como a cooperação, mas que inclui, também, os processos de interação, aprendizado, capacitação e inovação, considerados crescentemente como fundamentais para a sustentação da competitividade dos agentes participantes de aglomerações de empresas (CASSIOLATO; SZAPIRO, 2002).

Assim, torna-se relevante, na análise, a densidade das relações existentes entre os diversos atores do APL, considerando, ainda, as dinâmicas do capital social e da governança como categorias estratégicas para a sustentabilidade e competitividade desse tipo de arranjo organizacional.

\section{0 Capital Social e a Promoção da Governança}

O interesse acerca do tema "capital social" é recente entre os estudiosos da área organizacional. Primeiramente, as discussões sobre esse tema surgiram no âmbito da sociologia. De fato, foi Bourdieu (1985) que propagou esse termo na década de 80. Para esse teórico francês, o capital social, assim como as outras formas de capital, é desigualmente distribuído na sociedade, enfatizando, assim, o conflito de poder existente na estrutura social.

Por outro lado, Coleman (1988), sociólogo americano, enfatizou a interconexão entre sociologia e economia, ressaltando as relações entre educação e desigualdade social. Apesar da relevância desses autores, foi Putnam (1993) o responsável por popularizar o termo "capital social" com sua obra "Comunidade e democracia: a experiência da Itália. Putnam caracteriza o capital social de uma comunidade pelo fato deste se constituir um bem público, que facilita a cooperação espontânea, multiplicando-se em diferentes formas e manifestações, como as 'regras de reciprocidade', as 'redes de relações sociais', os 'sistemas de participação' e a 'confiança'.

Beretta e Curini (2003) definem o capital social como uma "expectativa generalizada de cooperação", destacando, portanto, a dimensão da 'cooperação' que termina por influenciar as formas de coordenação (governança) nas aglomerações produtivas territoriais.

Existem diferentes tipos de cooperação nos arranjos e sistemas produtivos locais, incluindo a 'cooperação produtiva', que visa à obtenção de economias de escala, à melhoria dos índices de qualidade e produtividade; e à 'cooperação inovadora', que resulta na diminuição de riscos, custos, tempo e, principalmente, no aprendizado 
interativo, favorecendo, assim, a ampliação do potencial de criação de competências produtivas e inovadoras (CASSIOLATO; LASTRES, 2003).

Corroborando com estas perspectivas, Albagli e Maciel (2003) destacaram que os componentes do capital social, favorecem os processos de inovação e de aprendizado interativo, criação e compartilhamento de conhecimentos, dimensões de fundamental importância para o dinamismo, gerando benefícios econômicos e sociais como, por exemplo: maior facilidade de compartilhamento de informações e conhecimento; criação de ambientes propícios ao 'empreendedorismo', contribuindo para o aumento de competitividade e sobrevivência sustentada das organizações dos arranjos; melhor coordenação e coerência de ações (governança), processos de tomada de decisão coletivos, bem como maior estabilidade organizacional, o que também contribui para diminuir custos; maior conhecimento mútuo entre os atores, reduzindo os riscos do oportunismo e favorecendo um maior compromisso com relação ao grupo.

Segundo Brusco e Solinas (1999), nas aglomerações produtivas de micros, pequenas e médias empresas, aquilo que rege práticas difusas de cooperação e possibilita a participação é um corpus complexo de regras - um código de confiança - que conforma os comportamentos dos atores. Esse código de confiança, intensamente discutido por Fukuyama (1996), envolve tanto as questões relacionadas à vida nos lugares de trabalho como, de forma mais geral, as condições externas, a vida associada.

O desenvolvimento desse 'código de confiança' que conforma o comportamento dos atores participantes nestas redes de cooperação se conecta com a discussão sobre a 'promoção da governança' no âmbito dos arranjos e sistemas produtivos locais. Na medida em que as ações deixam de ser cada vez menos individualizadas e tornam-se mais coletivizadas, faz-se necessária a constituição de uma força de coordenação das diversas ações, facilitando sinergias e garantindo o alcance dos objetivos desejados. A intensificação das relações entre as partes e o estabelecimento de uma coordenação dessas relações termina por promover a governança, atributo necessário à evolução do estágio de APL para SPL. Desta forma, o surgimento de uma 'boa' governança depende de um aprendizado que pode ser derivado da construção e consistência das ações coletivas (AMORIM et al, 2004).

Messner e Meyer-Stamer (2000), no seu texto intitulado Governance and network, salientaram que a governança, no âmbito dos sistemas produtivos, envolve o planejamento para a negociação entre os agentes participantes que interagem continuamente. Fazendo uso do modelo de Max Weber, os autores classificam três "tipos ideais" de governança:

1. A hierárquica (que se modela segundo os tradicionais instrumentos: dinheiro, poder e lei);

2. De mercado (com a coordenação baseada na "mão invisível"); e

3. Networks (desenvolvida através da dinâmica da negociação, reciprocidade e interdependência entre as partes envolvidas).

Humphrey e Schmitz (2000) apresentam, ainda, três categorias - a nível local e global - de governança (pública, privada e pública-privada), que por sua vez focalizam uma específica relação entre os agentes que operam em diversos âmbitos de atividades econômicas. 


\section{Quadro 1: Categorias privada, pública e pública-privada, a nível local e global de governança, das} atividades econômicas.

\begin{tabular}{ccc}
\hline & Nível Local & Nível Global \\
\hline Governança privada & $\begin{array}{c}\text { Associações empresariais locais } \\
\text { Clusters de empresas }\end{array}$ & $\begin{array}{c}\text { Cadeia global de fornecedores } \\
\text { Cadeia global de produção }\end{array}$ \\
\hline Governança pública & $\begin{array}{c}\text { Agências governamentais locais e } \\
\text { regionais }\end{array}$ & $\begin{array}{c}\text { WTO - Normas } \\
\text { Nacional e supra-nacionais normas } \\
\text { com posicionamento global }\end{array}$ \\
\hline Governança pública-privada & Políticas locais e regionais Redes & Padrões internacionais \\
& (Networks) & Campanhas de ONGS \\
& & internacionais \\
\hline
\end{tabular}

Fonte: Humphrey e Schmitz (2000)

Os autores pressupõem que o padrão de governança baseada em networks, colocada em ato através do elemento negociação, é crucial para os países em desenvolvimento, pois a lógica da interação e estilos de tomada de decisão nessas redes terminam por desencadear os processos de aprendizagem, influenciando o desenvolvimento da 'inovação social' (social innovation).

Segundo a Secretaria Executiva da Rede de Tecnologia Social (2004), a tradução possível para as Tecnologias Sociais (TS) é vista como um desafio igualmente teórico e prático. Para além de um conceito, as TS significam empreendimentos, organizações associativas, redes e iniciativas de cooperação. Também significam negócios, que geram emprego e renda, e antes de tudo o reconhecimento de que a fusão do saber popular com o conhecimento especializado proporciona ferramentas poderosas para a inclusão social e o progresso humano.

Assim, entendida como um processo de inovação a ser levado a cabo, coletiva e participativamente pelos atores interessados na construção de um cenário desejável, a TS se aproxima de algo que se denominou de 'inovação social' (DAGNINO; GOMES, 2000).

O conceito de inovação social, entendido ali a partir do conceito de inovação - concebido como o conjunto de atividades que pode englobar desde a pesquisa e o desenvolvimento tecnológico até a introdução de novos métodos de gestão da força de trabalho, e que tem como objetivo a disponibilidade por uma unidade produtiva de um novo bem ou serviço para a sociedade - é hoje recorrente no meio acadêmico e cada vez mais presente no ambiente das políticas públicas. Esse conceito engloba, portanto, desde o desenvolvimento de uma máquina (hardware) até um sistema de processamento de informação (software) ou de uma tecnologia de gestão organização ou governo - de instituições públicas e privadas (orgware).

O conceito de 'inovação social' é utilizado por Dagnino e Gomes (2000) para fazer referência ao conhecimento - intangível ou incorporado a pessoas ou equipamentos, tácito ou codificado - que tem por objetivo o aumento da efetividade dos processos, serviços e produtos relacionados à satisfação das necessidades sociais. Sem ser excludente em relação ao anterior, refere-se a um distinto código de valores, estilo de desenvolvimento, 'projeto nacional' e objetivo de tipo social, político, econômico e ambiental. Como o anterior, o conceito de inovação social engloba três tipos de inovação: hardware, software e orgware ${ }^{3}$.

Essas discussões, sobre o contexto relacional produtivo, institucional e social que caracterizam os APLs, ressaltam esta importante nuance do conceito de inovação. Inovação não é somente sinônimo de introdução de um novo processo produtivo ou, de um novo produto (material): inovação significa, também, o desenvolvimento de novas capacidades de relações e de projetos de serviços complexos, onde o objeto material é somente um componente da oferta final (RULLANI, 2003). Uma das prioridades parece ser a vontade de promover a inovação de forma ampla, criando um espaço, um ambiente que facilite a mobilidade das idéias, transformando-se em condutores de inovação, promovendo a co-operação seja no âmbito público, seja naquele privado e empreendedor. 


\section{Tecnologia Social (TS) de Mobilização dos Arranjos Produtivos Locais (APLs)}

A Tecnologia Social (TS) de Mobilização dos APLs, proposta neste ensaio, foi elaborada a partir da percepção das autoras deste trabalho de que existe uma necessidade de se implementar uma forma de atuação nesses arranjos organizacionais, que se diferencie daquelas tradicionais utilizadas no desenvolvimento de setores econômicos, e, sobretudo, das utilizadas no tratamento convencional de MPMEs. Essa última visão prioriza ações individualizadas e volta-se para as empresas tomadas de forma isolada, ignorando o conjunto de atores participantes de um determinado território e, a sinergia que pode ser gerada através do desenvolvimento do capital social e da governança existentes, mesmo que, de forma incipiente. Assim, através dessa Tecnologia Social (TS), pretende-se abrir uma discussão sobre formas reticulares e coletivizadas de mobilização dos arranjos produtivos locais (APLs), abrindo-se espaços para a inovação, objetivando-se ganhos de competitividade e, a transição do arranjo para um sistema produtivo local (SPL).

Considerando-se as regras metodológicas do pólo morfológico (BRUYNE et al.,1991) e baseando-se no conceito de capital social (PUTNAM, 1993; ALBAGLI; MACIEL, 2003; BERETTA; CURINI, 2003), enquanto redes de relações sociais que facilitam a cooperação e os sistemas de participação, articulando-se, ainda, o pressuposto teórico de "governança em rede" proposto por Messner e Meyer-Stamer (2000), propõe-se uma Tecnologia Social de Mobilização, sugerindo-se, desse modo, a criação de três entidades organizadas em rede.

As referidas entidades constituem instrumentos de mobilização social e baseiam-se em uma abordagem de aprendizagem cooperativa com o intuito de promover a inovação social por fundamentarem-se num processo a ser levado a cabo, coletiva e participativamente, pelos atores/agentes interessados no fortalecimento do capital social e da governança do território produtivo (DAGNINO; GOMES, 2000).

Parte-se da identificação de um grupo maior de atores selecionados ("Fórum para a Mudança") que, a partir da dinâmica de sua organização reticular, se desdobra em diversos grupos de trabalho ("Laboratórios para Inovação"), com foco em tarefas específicas, apontadas como prioritárias para a resolução dos problemas dos APLs. Por sua vez, esses grupos de trabalhos possuem mecanismos explícitos de ligação com instituições de referência ("Pontos de Escuta"), portadoras do estado-da-arte, referente a temas de preocupação específica dos APLs. Abaixo estão descritas as características dessas entidades.

\section{a) Fórum para a Mudança.}

Com o objetivo de facilitar a cooperação espontânea e considerando-se as diferentes formas de manifestação do capital social, descritas por Putnam (1993), como as redes de relações sociais e os sistemas de participação, propõe-se o 'Fórum para a Mudança' enquanto espaço organizacional através do qual os atores institucionais públicos e privados, envolvidos no APL, serão convidados a participar de um programa de mudanças.

Cassiolato e Lastres (2003) salientam que a 'cooperação inovadora', resultante do aprendizado interativo, amplia o potencial de criação de competências produtivas e inovadoras. Nesse contexto, o Fórum é um lugar de encontro e de difusão de idéias com o fim de assegurar uma relação entre as propostas de inovação e aqueles que serão chamados à gestão e a atuação das práticas específicas a cada contexto.

Por outro lado, a difusão dessas práticas de cooperação (BRUSCO; SOLINAS, 1999) derivante da reciprocidade, da interdependência, do planejamento e da negociação de um conjunto de ações coletivas termina por facilitar o desenvolvimento de um 'código de confiança' entre os atores/agentes participantes, reduzindo os riscos do oportunismo, favorecendo um maior compromisso com relação ao grupo, estabelecendo, assim, uma força de coordenação que promoverá, por fim, a governança em rede, entre as partes envolvidas (MESSNER; MEYER-STAMER, 2000; ALBAGLI; MACIEL, 2003).

A composição do Fórum deverá incluir os principais atores/agentes interessados no desenvolvimento do APL. Identificam-se as seguintes instituições que podem ser mobilizadas para participar do Fórum para a Mudança no Estado do Ceará. 


\section{Quadro 1: Composição do Fórum para Mudança}

\begin{tabular}{l}
\hline Ex Exemplos de Composição do "Fórum para a Mudança" \\
\hline Atores Selecionados \\
\hline 1) Lideranças do APL \\
\hline 2) Representante da Prefeitura Municipal \\
\hline 3) Representante do SEBRAE \\
\hline 4) Representante do Banco do Nordeste do Brasil -BNB \\
\hline 5) Representante do Governo Estadual \\
\hline 6) Membro do Clube dos Diretores Lojistas-CDL local \\
\hline 7) Representante do Banco do Brasil \\
\hline 8) Representante das Universidades com atuação no território \\
\hline 9) Representante dos CENTEC/CVTs presentes no território \\
\hline 10) Transportadoras, Correios (SEDEX) \\
\hline 11) Representante dos compradores e intermediários dos produtos do APL.
\end{tabular}

Fonte: Elaborado pelas Autoras.

\section{b) Laboratórios para a Inovação.}

O fortalecimento do capital social e a constituição de uma força de coordenação (governança) facilitada e articulada no Fórum favorecerão o aprendizado interativo, o compartilhamento de conhecimentos, os processos de inovação, a criação de ambientes propícios ao 'empreendedorismo', os processos de tomada de decisão coletiva, a estabilidade organizacional, etc., dimensões essas de fundamental importância para o dinamismo do APL, gerando benefícios econômicos e sociais (ALBAGLI; MACIEL, 2003). Nesse contexto propõe-se a criação dos Laboratórios para a Inovação composto por grupos de trabalho operativos, identificados a partir da dinâmica de atuação do Fórum e ativados para colocar em prática as propostas e ações de melhorias e desenvolvimento discutidas e decididas nos Fóruns.

Os Laboratórios para a Inovação são formados por representantes selecionados do Fórum e deverão oferecer soluções para problemas específicos, apontados pelos participantes do Fórum. Cada grupo operará em um arco de tempo definido, devendo manter interações sistemáticas com os demais membros do Fórum. Os Laboratórios terão, portanto, natureza e modalidades diferentes, tendo por objetivo o aumento da efetividade dos processos e produtos assim como o desenvolvimento de novas capacidades de relações e de projetos de serviços complexos (RULLANI, 2003), relacionados inclusive à satisfação das necessidades sociais (DAGNINO; GOMES, 2000). A partir de necessidades específicas, o Fórum instituirá novos Laboratórios para fazer face às novas questões que se apresentem como desafios. 


\section{Quadro 2: Objetivos dos Laboratórios para Inovação}

\begin{tabular}{l}
\hline Ex Exemplos de "Laboratórios para a Inovação" e seus objetivos \\
\hline 1. Observatório nacional e internacional sobre as novas tendências tecnológicas \\
\hline 2. Criação de um pool para a prospecção de novos mercados, canais de distribuição nacionais e \\
internacionais \\
\hline 3. Desenvolvimento de práticas cooperativas (relações e trocas) inter-empresas e inter-arranjos \\
\hline $\begin{array}{l}\text { 4. Relações com o crédito bancário e desenvolvimento de formas de financiamento customizados e } \\
\text { coletivo }\end{array}$ \\
\hline 5. Ações focalizadas no processo de inovação, design e diversificação \\
\hline 6. Projetos comuns para a formação e desenvolvimento dos Recursos Humanos \\
\hline 7. Desenvolvimento de novas competências técnicas (skills). Exemplos: design, logística e marketing \\
\hline 8. Gestão de problemas comuns do ambiente \\
\hline 9. Criação de uma rede de parcerias com autoridades públicas e governo estadual, municipal e federal \\
\hline 10. Interação e coesão entre vários sujeitos produtivos e institucionais (nacionais e internacionais) para \\
trocas de best-practices \\
\hline 11. Ações de marketing social e cultural relacionadas com o desenvolvimento da imagem (aspectos \\
intangíveis) do território \\
\hline 12. Promoção de ações comerciais entre as MPMEs e entre os APLs \\
\hline 13. Estímulo ao ‘empreendedorismo’ e ao controle de MPMEs emergentes \\
14. Relações entre contratadas e sub-contratadas
\end{tabular}

Fonte: Elaborado pelas Autoras.

\section{c) Pontos de Escuta.}

Grande parte da literatura insiste em acentuar que, para desenvolver-se, um APL deve balancear dinamicamente o grau de vitalidade interna do seu tecido (sinergia interna) com aquele de abertura para o mundo (participação em redes globais ou relações externas) (IPIRANGA, 2006).

Considerando essas discussões, alguns pesquisadores (MAGGIONI; RIGGI, 2002) desenvolveram estudos, simulando diversos cenários de interação - através dos dois canais alternativos de aprendizagem coletiva - "as conexões internas e as conexões externas" - para verificar as implicações sobre o processo de criação e difusão da inovação que se nutre do tecido (social, cultural, institucional, tecnológico e produtivo) no qual estão localizadas as MPMEs.

Segundo os estudos de Maggioni e Riggi (2002), especificamente no caso das conexões externas, foi considerado que o contato com o externo permite às empresas aprender e melhorar sua performance. Esse contato acontece somente quando a empresa se aproxima de uma "janela tecnológica" (technological windowing) por um período de tempo suficiente para observar, imitar e metabolizar a inovação.

Os Pontos de Escuta têm o objetivo de funcionar como uma janela tecnológica para o mundo externo ao território produtivo, representando fontes de novas idéias com possível aplicabilidade para os APLs ali localizados. Cada Laboratório poderá ter um ou mais Pontos de Escuta, que deverão ser selecionados, a partir da natureza da atividade produtiva. É importante que participantes dos Laboratórios tenham contatos e conexões externas permanentes em cada Ponto de Escuta para facilitar as interações e acesso ao conhecimento novo. Não é necessário que os participantes dos Pontos de Escuta estejam físicamente presentes nos Laboratórios, podendo o contato ser concretizado inclusive por meio virtual. Os Pontos de Escuta podem ser instituições tradicionais, ou simplesmente referências ou entidades virtuais (ex.: páginas na web; formação de consórcios temporários entre as empresas para organizar eventos tais como a participação em uma feira tecnológica, no estrangeiro, ou mesmo nacional, mas externa ao território do arranjo). 
A seguir apresenta-se a arquitetura da Tecnologia Social de Mobilização dos APLs para uma melhor visualização da sua dinâmica de organização reticular.

\section{Diagrama 1 - Tecnologia de Mobilização Social através de uma Abordagem Cooperativa}

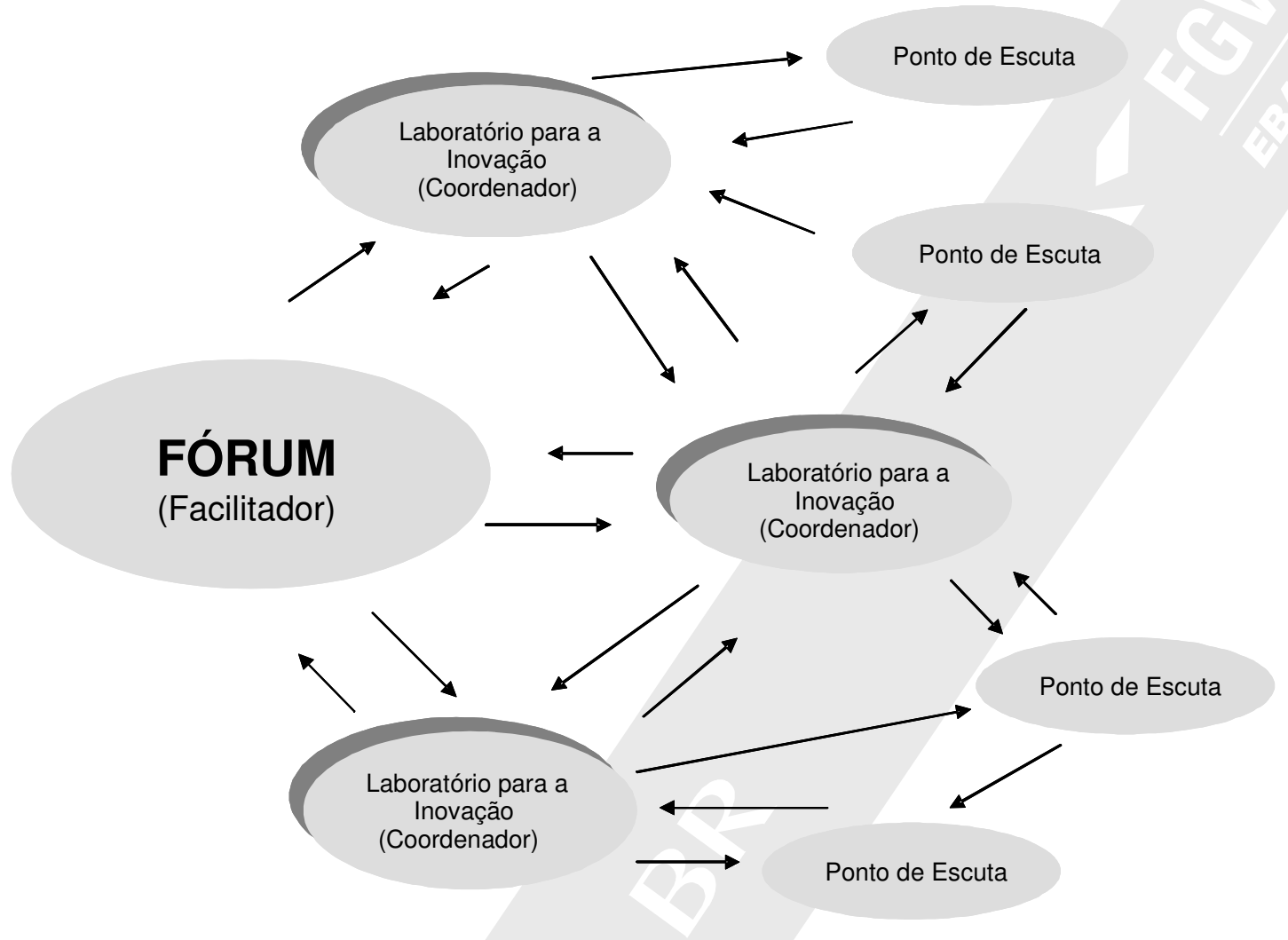

O diagrama, acima, demonstra que as três entidades organizacionais estão intensamente inter-relacionadas, constituindo uma rede de relações que fortalecem a interdependência produtiva e inovadora, exercitando uma colaboração eficiente com a circulação das informações, encadeamento de ações e ganhos de aprendizado e eficiência produtiva. A partir desse inter-relacionamento e à medida que as conversações e negociações entre os atores/agentes envolvidos avançam, vão sendo definidos os conjuntos de ações através da Tecnologia de Mobilização, possibilitando a aprendizagem cooperativa e a inovação social (DAGNINO; GOMES, 2000). Durante todo o processo, o gerenciamento da Tecnologia Social (TS) é realizado através da utilização de instrumentos e mapeamentos empíricos elaborados e implementados pelos atores/agentes envolvidos em cada instância de participação, tais como avaliação, verificação dos impactos e implicações no território referentes à aplicação dessa Tecnologia. Na medida em que facilita o inter-relacionamento, o aprendizado e a inovação, a organização e a vivência prática dessa rede de inter-relações poderá se constituir em um mecanismo eficaz para facilitar a evolução do APL para uma estrutura mais complexa como os SPLs.

Em seguida será apresentada uma possível aplicação da Tecnologia Social, anteriormente estruturada, em dois arranjos produtivos locais (APLs) no Estado do Ceará. 


\section{A aplicação da Tecnologia Social (TS): APLs de redes de dormir de Jaguaruana/CE e de crochê de Nova Russas/CE}

Considerando-se que as Tecnologias Sociais - TS (2004) são vistas como um desafio igualmente teórico e prático, nesta seção, tendo-se como referência os pólos técnico e morfológico da prática metodológica, propostos por Bruyne et al (1991), procede-se a uma aplicação da TS, descrita anteriormente, em dois arranjos produtivos locais (APLs), localizados no Ceará. Os setores de atuação dos casos sob estudo são bem diversificados e com forte tradição local, quais sejam: artesanato em crochê da cidade de Jaguaruana (CE) e redes de dormir da cidade de Nova Russas (CE).

Para isso foi realizada uma pesquisa exploratória através de visitas nos dois APLs selecionados, possibilitando o reconhecimento dos territórios através dos procedimentos da observação participante (durante reuniões e conversas informais com os atores/agentes dos APLs) e de entrevistas com informantes-chave das diversas instituições e das micros, pequenas e médias empresas localizadas nos arranjos, bem como levantamento de dados secundários através da análise documental.

A compilação e a análise desses dados possibilitaram a identificação dos atores/agentes presentes nos territórios dos arranjos sob estudo. A situação de cada arranjo também foi previamente diagnosticada, propondo-se, assim, uma possível dinâmica de mobilização participativa, tecendo relações, ao envolver os atores institucionais, comunitários e produtivos atuantes no território. Com base na Tecnologia Social de Mobilização dos APLs proposta, essa dinâmica sugere a constituição de uma rede de inter-relações entre os atores, com potencial de gerar sinergias, para avançar de forma inovadora em prol do desenvolvimento do arranjo produtivo local (MESSNER; MEYER-STAMER, 2000; ALBAGLI; MACIEL, 2003).

Descrevem-se, a seguir, as características e as propostas de mobilização dos dois APLs, observados através de uma possível constituição das entidades organizacionais ("Fórum para a Mudança", "Laboratórios para Inovação" e "Pontos de Escuta") previstas na Tecnologia Social (TS).

\subsection{Arranjo produtivo local de redes de dormir de Jaguaruana/CE}

O arranjo produtivo do Município de Jaguaruana caracteriza-se pela produção de redes de dormir. A produção de fios existe há mais de um século, desde quando aquela região era uma grande produtora de algodão no Estado. Com abundância de matéria-prima, os índios Jaguaruanas (em Tupi Onça Preta) que ali viviam, passaram a fabricar redes para uso próprio. A produção de redes faz parte, portanto, da cultura e tradições locais, caracterizando-se como uma atividade predominantemente familiar.

Num período mais recente, o grupo Santista montou uma fábrica para o beneficiamento do algodão, semeando o território com uma miríade de pequenos estabelecimentos industriais para manufaturarem o fio. Desde então, essa produção se tornou a principal atividade econômica do Município.

Atualmente o APL de Redes de Dormir de Jaguaruana emprega diretamente cerca de 1.900 pessoas e possui aproximadamente 200 unidades produtivas. A atividade apresenta grande potencial de exportação, contudo a produção de redes em Jaguaruana enfrentou períodos de declínio; o individualismo e a desconfiança dos pequenos produtores impediam que o trabalho cooperativo e a geração de sinergias atuassem na superação das dificuldades que se apresentavam.

Os pequenos produtores do APL de Jaguaruana tinham problemas de inserção de seus produtos no mercado, com a concorrência do arranjo produtivo de São Bento, na Paraíba, que oferece produtos símiles a um preço mais baixo. Apesar dos produtos do APL serem bem aceitos em mercados europeus, os produtores, individualmente, se deparavam com diversas dificuldades na produção, desde aquisição de insumos (falta capital de giro, acesso ao crédito, etc), ao escoamento da produção (pagamento de fretes, emissão de notas fiscais, etc). 
Tendo por base essas dificuldades em 2002, o APL iniciou uma nova fase de desenvolvimento, com a promoção da governança local pública e privada que se efetivou na realização de projetos de apoio e fomento à atividade produtiva de redes de dormir por meio de ações articuladas e conjuntas, entre diversas entidades e instituições. A partir das ações desenvolvidas, os pequenos empresários participantes intensificaram as relações cooperativas para empreenderem de forma coletiva, resultando na organização e criação da Associação dos Fabricantes de Redes de Jaguaruana - ASFARJA.

\subsubsection{Proposta de mobilização do APL de redes de dormir de Jaguaruana: constituição do "Fórum para a Mudança", "Laboratórios para Inovação"e "Pontos de Escuta".}

Considerando-se o pressuposto, segundo Messner; Meyer-Stamer (2000), que o padrão de governança baseada em networks, colocada em ato através do elemento negociação, é crucial para os países em desenvolvimento, torna-se essencial que exista um esforço, por parte dos atores/agentes integrantes do APL, para a construção de uma rede de inter-relacionamento e dinamização da cooperação (PUTNAM, 1993; ALBAGLI; MACIEL, 2003; BERETTA; CURINI, 2003).

Essa rede poderá ser operacionalizada a partir da constituição de três entidades organizacionais ("Fórum para a Mudança", seus "Laboratórios" e respectivos "Pontos de Escuta"), desencadeando, assim, os processos de aprendizagem cooperativa e influenciando o desenvolvimento da inovação social (DAGNINO; GOMES, 2000). Com base nos conceitos e pressuposto anteriormente expostos apresenta-se, a seguir, uma breve descrição da constituição dessas entidades no APL sob estudo.

\subsubsection{Fórum para a Mudança}

No caso do APL de Jaguaruana, sugere-se que o Fórum para a Mudança poderá ser constituído a partir de representantes das seguintes entidades localizadas no território do APL e na capital do estado:

\section{Quadro 3: Fórum para a Mudança}

\begin{tabular}{l}
\hline Fórum para a Mudança \\
\hline Associação de produtores (ASFARJA), demais produtores não ligados à associação; \\
\hline Prefeitura; \\
\hline SEBRAE-CE; \\
\hline BNB; \\
\hline Banco do Brasil; \\
\hline Clube dos Diretores Lojistas (CDL) local; \\
\hline Representante da Secretaria da Fazenda; \\
\hline Correios; \\
\hline Cento de Ensino Tecnológico (CENTEC) de Limoeiro do Norte; \\
\hline SENAI; \\
\hline Curso de Graduação em Estilismo (Universidade Federal do Ceará-UFC); \\
\hline Sindicato das Indústrias de Fiação
\end{tabular}

Fonte: Elaborado pelas Autoras.

\subsubsection{Laboratórios para Inovação}

Propõe-se que o encaminhamento das propostas formuladas e priorizadas no Fórum seja realizado através de diversos Laboratórios para Inovação, criados pelos participantes do Fórum. Os Laboratórios se ligam a problemas específicos, cujas soluções são definidas como prioritárias pelo Fórum. Abaixo, adiantam-se sugestões para alguns desses Laboratórios, assim como seus objetivos e componentes. 


\subsubsection{Laboratório para Inovação em Desenvolvimento de Competências}

Esse Laboratório tem como foco a produção de competências inovadoras, tanto para as pessoas (capital humano), grupos (coesão e articulação grupal), como para as organizações (desenvolvimento organizacional) e empresas do APL.

Desde o princípio, a instalação e o funcionamento do Fórum, Laboratórios para a Inovação e Pontos de Escuta necessitarão que os atores envolvidos tenham uma preparação prévia para trabalhar em grupo. Recomenda-se, assim, que sejam oferecidos aos atores do APL, cursos de formação básica e vivências em atividades grupais, organização coletiva, associativismo e cooperativismo.

\section{Quadro 4: Laboratório para Inovação em Desenvolvimento de Competências - Exemplos de Ações}

\begin{tabular}{l}
\hline Exemplos de Ações \\
\hline Vivência em relacionamento interpessoal; \\
\hline Vivência em dinâmicas grupais (destinada a estimular a interação e a confiança entre os membros do \\
APL); \\
\hline Curso de associativismo e cooperativismo; \\
\hline Curso sobre segurança e higiene do trabalho; \\
\hline Curso sobre legislação trabalhista; \\
\hline Oficinas sobre constituição de redes de empresas;
\end{tabular}

Fonte: Elaborado pelas Autoras.

\subsubsection{Laboratório para Inovação em Tecnologia e Design}

Voltado para pesquisar tendências, estilos e novas oportunidades para diversificação, valorização da produção do APL e melhorias na qualidade dos produtos (ex.: uso de novos pigmentos, novas matérias primas, etc). Como exemplo de intervenções desse Laboratório, pode-se mencionar a identificação de profissionais capazes de ministrar cursos, oficinas e prestar serviços de consultoria aos produtores. Outro exemplo seria o acerto de parcerias com o SENAI e com o curso de graduação em Estilismo da Universidade Federal do Ceará (UFC), tendo em vista aperfeiçoar o design e o estilo dos produtos fabricados no APL. 


\section{Quadro 5: Laboratório para Inovação em Tecnologia e Design - Exemplos de Ações}

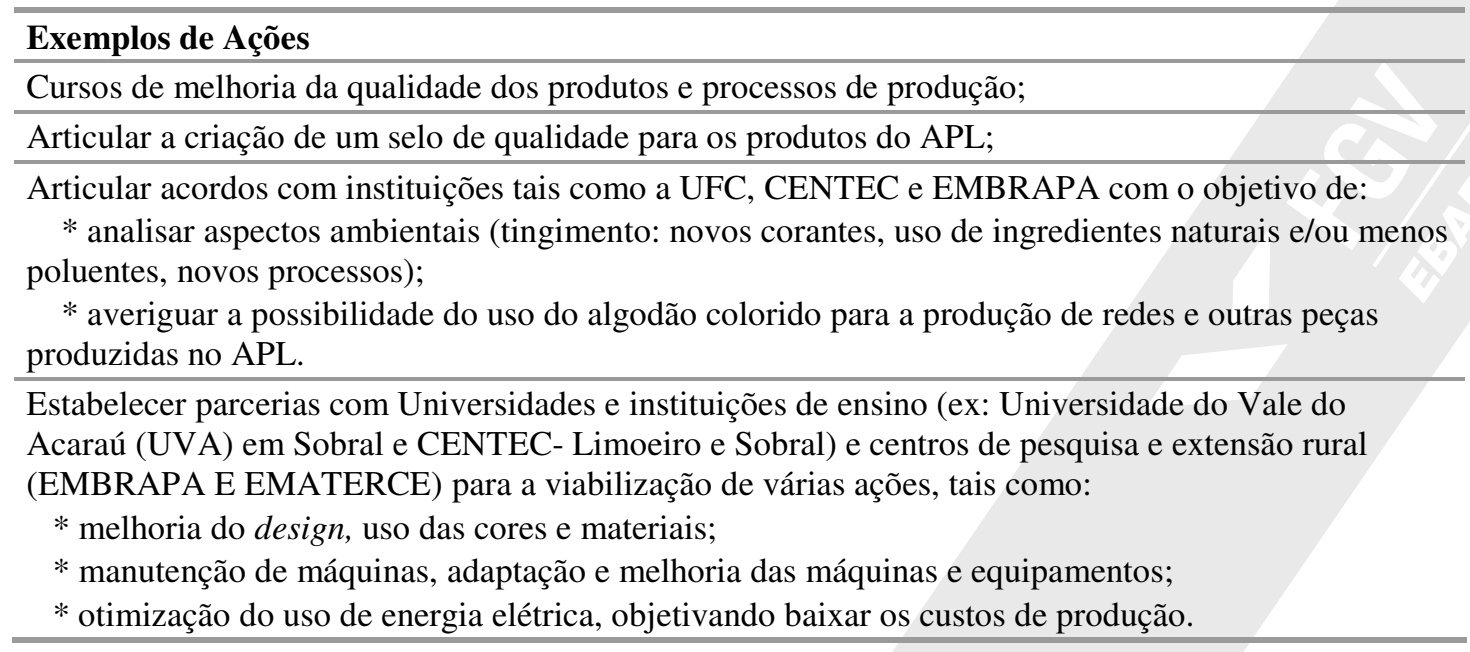

Fonte: Elaborado pelas Autoras.

\subsubsection{Laboratório para Inovação em Finanças}

Destinado a discutir com técnicos da Secretaria da Fazenda Estadual (SEFAZ) alternativas para resolver problemas relacionados à cobrança do ICMS relativo a fios e redes no Estado, emissão de nota fiscal, trânsito de mercadorias e outros temas relacionados, assim como temas relativos a custos e formação de preço.

Quadro 6: Laboratório para Inovação em Finanças - Exemplos de Ações

\section{Exemplos de Ações}

Articular, com as Secretarias do Desenvolvimento Econômico, Trabalho e ‘Empreendedorismo’ e

Fazenda, um grupo de trabalho para discutir e equacionar os problemas fiscais enfrentados pelos produtores do APL;

Discutir uma política de preços para o APL, desenvolver métodos eficazes de controle de custos e de formação de preços;

Acompanhar a evolução das vendas do APL;

Discutir medidas voltadas para o controle da inadimplência (ex.: cadastro comum dos compradores, consultas dos cheques, divulgação dos compradores inadimplentes etc).

Articular, com a prefeitura, órgãos estatais e ONGs, um fundo de aval para viabilizar empréstimos (inclusive capital de giro) para os produtores do APL;

Fonte: Elaborado pelas Autoras.

\subsubsection{Laboratório para Inovação em Comunicação, Marketing e Expansão de Mercado}

Busca desenvolver ações voltadas para a prospecção e expansão de mercado para o APL, criação e desenvolvimento da marca dos produtos locais, novas formas de comercialização. 


\section{Quadro 7: Laboratório para Inovação em Comunicação e Marketing - Exemplos de Aç̃̃es}

\begin{tabular}{l}
\hline Exemplos de Ações \\
\hline Elaboração de um catálogo para divulgação dos produtos dos dois APLs; \\
\hline Apoiar a elaboração de uma página do APL na Internet. (É importante prever recursos para financiar \\
apoio técnico e suporte operacional a essas duas iniciativas); \\
\hline $\begin{array}{l}\text { Articular, junto ao poder público e instituições privadas, a construção de show room para divulgação } \\
\text { dos produtos em Jaguaruana; }\end{array}$ \\
\hline $\begin{array}{c}\text { Articular, com a agência dos Correios em Jaguaruana, um convênio com os produtores do APL para } \\
\text { tarifas diferenciadas e prazo estendido para o pagamento do frete. }\end{array}$ \\
\hline
\end{tabular}

Fonte: Elaborado pelas Autoras.

\subsection{Pontos de Escuta}

Conforme dados coletados durante as observações, contatos e entrevistas realizadas, os Pontos de Escuta para o APL de Jaguaruana podem incluir as seguintes instituições e organizações de referência enquanto canais externos e internos de informações (MAGGIONI; RIGGI, 2002): Universidade Federal do Ceará - UFC (Cursos de Estilismo e Moda, Agronomia, Química Industrial, Meio Ambiente, Engenharia Mecânica etc); Universidade Estadual do Ceará - UECE (curso de Administração de Empresas, Comércio Exterior, Políticas Públicas); EMBRAPA (pesquisas e estudos sobre o algodão); Sindicato das Indústrias de Fiação e Tecelagem (questões relacionadas ao fio, impostos, mercados, etc.); Centro de Informações Internacionais - CIN da Federação das Indústrias do Ceará - FIEC; Banco do Nordeste - BN; corretores de produtos de tecelagem e agentes de comércio exterior, bem como representações de países estrangeiros no Ceará, por exemplo: Alemanha que tem demonstrado interesse nos produtos do APL.

\section{Arranjo produtivo local de Crochê de Nova Russas/CE}

O arranjo produtivo do Município de Nova Russas tem como atividade produtiva a confecção artesanal de artigos em crochê. São aproximadamente 10.000 crocheteiras em atividade em Novas Russas e em mais outros três municípios no seu entorno. Como no caso anterior, a atividade de crochê também faz parte da tradição de Nova Russas e ainda constitui uma importante fonte de receita para o Município. De fato, estimativas informais apontam que a receita gerada por esta atividade, freqüentemente supera a receita municipal, incluindo arrecadação própria e transferências relativas ao Fundo de Participação dos Municípios-FPM, o que constitui um fato extraordinário, em se tratando do Nordeste brasileiro.

\subsection{Proposta de mobilização do APL de Nova Russas: constituição do "Fórum para a Mudança", "Laboratórios para Inovação" e "Pontos de Escuta".}

O APL de Nova Russas já conta com uma associação (Associação das Crocheteiras de Nova RussasASCRON), mas que envolve apenas $10 \%$ das crocheteiras que trabalham na região. Faz-se necessário, assim, ampliar o nível de engajamento e participação dos atores tanto produtivos, tanto institucionais como comunitários, para uma maior discussão e resolução dos problemas em comum, amadurecendo, assim, a prática coletiva e a promoção de ações inovadoras (PUTNAM, 1993; ALBAGLI; MACIEL, 2003; BERETTA; CURINI, 2003). Esse processo visa a fortalecer os laços cooperativos entre os atores/agentes produtores do APL com representantes do poder público local e membros da sociedade civil (representantes de comunidades, instituições de fomento a pesquisa e ao crédito), através de encontros periódicos e de organização de palestras e oficinas participativas para discussão de questões locais (RULLANI, 2003; DAGNINO; GOMES, 2000). O processo poderá, portanto, ser acionado através da referente Tecnologia Social (TS), favorecendo a mobilização social dos atores/agentes presentes no território, visando a uma maior intensificação das relações e promovendo a densidade sistêmica através da constituição de redes de cooperação (MESSNER; MEYER-STAMER, 2000; CASSIOLATO; LASTRES, 2003). 


\subsubsection{Fórum para a Mudança}

No Fórum para a Mudança poderão tomar parte representantes de todos os setores envolvidos na atividade de crochê do município e seu entorno. Foram identificadas as seguintes instituições que podem ser representadas no Fórum deste APL.

Quadro 8: Fórum para a Mudança

\begin{tabular}{l}
\hline Fórum para a Mudança \\
\hline Associação de Produtores (ASCRON); \\
\hline SEBRAE-CE; \\
\hline Prefeitura Municipal/SEDEMA (Secretaria de Desenvolvimento Econômico e Meio Ambiente); \\
\hline Representante do Governo do Estado (SEFAZ-CE, CEART- Centro de Artesanato do Ceará); \\
\hline Banco do Brasil; \\
\hline Banco do Nordeste do Brasil (BNB); \\
\hline Universidade Federal do Ceará/Curso de Estilismo e Moda; \\
\hline Dragão Fashion (Organização de Estilistas Profissionais do Ceará); \\
\hline Representante do Clube dos Diretores Lojistas-CDL local; \\
\hline Representantes dos compradores e fornecedores; \\
\hline Representantes de ONGs.
\end{tabular}

Fonte: Elaborado pelas Autoras.

\subsubsection{Laboratórios para Inovação}

Foi identificada, neste APL, a necessidade de tornar mais visível essa atividade produtiva, que é de tamanha importância para o município. Em geral, não há difusão de informações sobre essa atividade no Estado, o que restringe possibilidades de inserção de seus produtos em mercados mais amplos. Além disso, é importante aprimorar o design dos produtos ali fabricados e trabalhar as diversas competências do grupo de produtores. Para esse arranjo, sugerem-se os três Laboratórios a seguir.

\subsubsection{Laboratório de Comunicação, Marketing e Expansão de Mercado}

Tem, como foco, estratégias direcionadas à comunicação visual com ênfase em marketing, visando a oferecer maior visibilidade aos produtos fabricados pelo APL, tais como: marketing territorial, elaboração de planos de marketing, divulgação dos produtos, veiculação de informação acerca da atividade produtiva em nível local, nacional e internacional entre os produtores. 


\section{Quadro 9: Laboratório para Inovação em Comunicação e Marketing - Exemplos de Ações}

\begin{tabular}{l}
\hline Exemplos de Ações \\
\hline Programação visual da cidade, estradas e entorno; \\
\hline Inserção de informações no portal do Sebrae, BN, lojas da CEART, Mercado Central, EMCETUR \\
(centro de artesanato e turismo), Estação Rodoviária de Fortaleza; \\
\hline Prospecção de novos mercados: elaboração de Catálogos de produtos, folders e demais materiais \\
promocionais; \\
\hline Publicidade direcionada para compradores potenciais (ex.: envio de mala direta); \\
\hline Inserção de matérias em revistas especializadas (ex. "Moda Quente”, "Manequim"); \\
\hline Construção da home page do APL; \\
\hline Inserção em feiras regionais e nacionais; \\
\hline Instalação de um show-room (exemplo: no prédio do mercado municipal ou ao longo da estrada que \\
corta o município); \\
\hline Elaboração do Cadastro dos compradores; \\
\hline Criação da marca (a partir de pesquisa histórico-cultural) e de selos de qualidade para os produtos; \\
\hline $\begin{array}{l}\text { Diversificação: uso de peças de crochê em peças diversas de confecções, ex: moda praia, jeans, } \\
\text { vestuário feminino, bolsas etc. }\end{array}$ \\
\hline Articular, com a agência de correios de Nova Russas, um convênio com os produtores do APL para \\
cobrança de tarifas diferenciadas e prazo estendido para pagamento do frete.
\end{tabular}

Fonte: Elaborado pelas Autoras.

\subsubsection{Laboratório de Tecnologia e Design}

Tem como objetivo pesquisar tendências, estilos e novas oportunidades para diversificação e valorização da produção do APL, melhorias na qualidade dos produtos (combinação de cores, modelagens, novos materiais etc). Como exemplo de intervenções desse Laboratório pode-se mencionar a identificação e contratação de profissionais especializados capazes de ministrar cursos e prestar serviços de consultoria aos produtores. Outro exemplo seria acertar parcerias com o SENAI e com o curso de Estilismo da UFC, tendo em vista aperfeiçoar o design e o estilo dos produtos fabricados no APL.

\section{Quadro 10: Laboratório para Inovação em Tecnologia e Design - Exemplos de Ações}

Exemplos de Ações

Articular colaboração com o Centro Ceará Design, SENAI, curso de Estilismo (UFC) e Dragão

Fashion: design, modelagem, montagem de coleção, uso de cores, formas e novos materiais, financiar trabalhos de conclusão de curso e consultorias diversas, com, por exemplo, noções sobre cromatografia;

Facilitar a criação de canais de informação entre:

(i) produtores, lojistas e fabricantes de linhas (catálogo de cores, mostruário de novos produtos, indicação de tendências);

(ii) produtores e compradores (sugestões para mudança nos padrões, tamanhos, etc).

Fonte: Elaborado pelas Autoras.

\subsubsection{Laboratório de Desenvolvimento de Competências}

Tem como foco o desenvolvimento de competências inovadoras, tanto para as pessoas (capital humano), grupos (coesão e articulação grupal), como para as organizações (desenvolvimento organizacional), envolvendo as empresas e as demais instituições presentes no território do APL. 


\section{Quadro 11: Laboratório para Inovação em Desenvolvimento de Competências - Exemplos de Ações}

\begin{tabular}{l}
\hline Exemplos de Ações \\
\hline Capacitação Social: promoção de exercícios de vivências em desenvolvimento interpessoal, dinâmicas \\
grupais e formação da confiança. Noções de associativismo e cooperativismo; \\
\hline Cursos de Técnicas de Venda e Exportação: deve incluir legislação, noções sobre como formar \\
consórcio de exportação, procedimentos técnicos para exportar; \\
\hline 'Empreendedorismo'(motivação, visão de negócio); Associativismo e cooperativismo; \\
Cursos de Noções de Custos: destina-se a oferecer aos produtores noções mínimas de cálculo de custos \\
e de 'precificação' apropriada para os produtos do APL; \\
\hline Cursos de Alfabetização: ação importante, tendo em vista a quantidade de pessoas adultas que ainda não \\
conseguem ler, interpretar e escrever;
\end{tabular}

Fonte: Elaborado pelas Autoras.

\subsection{Pontos de Escuta}

Várias instituições poderiam participar como Pontos de Escuta para esse APL, dentre elas destacam-se: Dragão Fashion, SENAI, home pages (São Paulo Fashion Week, Textília (revista têxtil), Universidade Anhembi, revistas especializadas, feiras regionais e nacionais, desfiles de moda (Fortaleza Fashion Week, Iguatemi Fashion Week), UFC/Curso de Estilismo, CIN/FIEC/SEBRAE, centros de tecnologia têxtil e fabricantes de linhas. Da mesma forma, o propósito consiste em coletar, dos ambientes e canais externos ao APL, idéias e informações novas que possam, quando internalizadas, promover o desenvolvimento e fortalecimento do APL (MAGGIONI; RIGGI, 2002).

\section{Considerações Finais}

O estudo de aglomerações produtivas, com enfoque na abordagem de arranjos e sistemas produtivos locais, oferece uma compreensão abrangente da dinâmica do funcionamento das MPMEs com foco no território, pois demonstra como a competitividade de um aglomerado produtivo é influenciada por fatores como capital social, governança e práticas cooperativas.

Este ensaio, ao considerar a abordagem metodológica de Bruyne et al (1991), teve o objetivo de ilustrar, através de uma aplicação em dois casos empíricos, uma "Tecnologia Social (TS) de Mobilização de Arranjos Produtivos Locais (APLs)," elaborada a partir das articulações entre o conceito de capital social (PUTNAM, 1993; ALBAGLI; MACIEL, 2003; BERETTA; CURINI, 2003)) e o pressuposto da governança em rede (MESSNER ; MEYER-STAMER, 2000), sugerindo, assim, a criação de três tipos de entidades organizacionais que, articuladas em rede, podem contribuir para a inovação social (DAGNINO; GOMES, 2000) através do fortalecimento do capital social e da governança nos territórios dos APLs.

A aplicação da Tecnologia Social (TS), nos dois casos de APLs observados, identificou os atores/agentes localizados nos territórios produtivos dos arranjos. A situação de cada arranjo também foi previamente diagnosticada e propôs, por fim, uma possível dinâmica de mobilização participativa, envolvendo os atores institucionais, comunitários e produtivos, atuantes, sugerindo a constituição de uma rede de inter-relações, com potencial de gerar sinergias para avançar de forma inovadora em prol do desenvolvimento do arranjo produtivo local.

A "Tecnologia Social (TS) de Mobilização do APL" sugere a criação de três tipos de entidades cuja organização em rede se baseia em uma abordagem de aprendizagem cooperativa. Parte-se da identificação de um grupo maior de atores selecionados ("Fórum para a Mudança") que, a partir da sua dinâmica de organização, se desdobra em diversos grupos de trabalho ("Laboratórios para Inovação") com foco em tarefas específicas, apontadas como prioritárias para a resolução dos problemas do APL. Por sua vez, esses grupos possuem mecanismos explícitos de ligação com instituições de referência internas e externas ao APL ("Pontos de Escuta"), portadoras do estado-da-arte referente a temas de ocupação específica do APL. 
A idéia de criação e operação do "Fórum para a Mudança" visa a facilitar o envolvimento dos atores/agentes em uma rede de relações, intensificar sua convivência, encorajar ações coletivas, organizadas e sistemáticas, catalisando, assim, essa ambiência cooperativa de aprendizagem, fortalecendo, por fim, o capital social do APL. Por outro lado, o encaminhamento sistemático de soluções para os problemas do APL propicia sua coordenação, promovendo, portanto, a governança. Esses dois ativos, capital social e governança, constituem fatores essenciais para a sustentabilidade e competitividade dos APLs. Além disso, o fortalecimento do capital social e a promoção da governança são elementos fundamentais para a criação da inovação social e consequientemente a transformação dos arranjos em sistemas produtivos locais. Todo o esforço de criação dessa rede de inter-relações apresentada tem como objetivo promover essa transformação.

A contribuição almejada por este trabalho consiste em disponibilizar uma "Tecnologia Social (TS) de Mobilização", vista como um desafio igualmente teórico e prático, que possa concretamente fortalecer os arranjos produtivos locais (APLs), aumentando a quantidade e a intensidade das ligações reticulares desses com outros atores/agentes presentes no território, de modo a ampliar o leque de sustentação e apoio para os mesmos. O "Fórum para a Mudança", os "Laboratórios de Inovação" e os "Pontos de Escuta" cumprem a função de unir esforços para identificar oportunidades e recursos de diversas modalidades, traçar uma estratégia para alcançálos e utilizá-los de forma objetiva para o desenvolvimento dos arranjos produtivos locais.

Como próximo passo para o desenvolvimento dessa abordagem, indica-se a implementação dessa Tecnologia Social, de modo a testar sua exeqüibilidade e efetividade. Isto seria viável através de um pacto social promovido entre a governança do APL e o poder local voltado para o desenvolvimento do território em questão.

O resultado final desse esforço teórico-metodológico poderá, ainda, oferecer subsídios para a formulação de uma política pública para intervenção produtiva nos territórios, visando ao fortalecimento das aglomerações de micro, pequenas e médias empresas, inclusive contemplando a elaboração de instrumentos de avaliação contínua que permitirão os ajustes adequados a cada realidade enfocada. 


\section{Bibliografia.}

ALBAGLI, S. BRITO, J. Arranjos Produtivos Locais: Uma nova estratégia de ação para o SEBRAE - Glossário de Arranjos Produtivos Locais. Rede Sist, 2002.

ALBAGLI, S.; MACIEL,M.L. Capital social e 'empreendedorismo' local . Proposição de política para a promoção de sistemas produtivos locais de micro, pequenas e médias empresas. 2003. Disponível em:< www.ie.ufrj.br/redesist>. Acesso em 18.06.2006.

AMARAL FILHO, J. do. "A 'endogeinização' no desenvolvimento econômico regional". In: XXVII ENCONTRO NACIONAL DA ANPEC, Belém, Anais..., Belém, p. 1281-1300, dez. 1999.

AMORIM, M. Clusters como estratégia de desenvolvimento industrial no Ceará. Fortaleza, Banco do Nordeste, ETENE, 1998.

AMORIM.A.A.; MOREIRA, M.V.; IPIRANGA, A.S. R. "Constructing governance within small firm cluster: a view from the developing world". In: Buildind a sustainable city through sustainable enterprise. Chicago - USA: BELL CONFERENCE IIT - Stuart Graduate School of Illinois, 2004.

AUDRETSCH, D. B. Agglomeration and the location of innovative activity. Oxford Review of Economic Policy 14: 2,Verão,1998.

BAPTISTA, C. Distritos flexiveis e desenvolvimento endógeno: Uma abordagem "marshalliana". Disponivel em:< http://www.geocities.com/statprof/distrit.html.>. Acesso em: 20.01.2003

BRITTO, J.; ALBUQUERQUE, E. da M. Caracteristicas estruturais de Clusters Industriais na economia brasileira: uma análise inter-setorial. Disponivel em: <http:www.nepp.unicamp.br/cadernos/cadernos/caderno 39.pdf> . Acesso em: 22. 01.2003

BERETTA, S.; CURINI, L. "Il ruolo della famiglia nel generare capitale sociale: um approccio di economia política". In: VIII Rapporto CISF sulla famiglia in Itália, Milano: S. Paolo, p. 290-339, 2003.

BOURDIEU, P. The forms of capital. In: RICHARDSON, J.G. (ED) Handbook of theory and research for sociology of education. New York: Greenwood, 1985, p.241-258.

BRUSCO, S. The idea of the industrial districts: its genesis. In: PYKE, F. et al. Industrial districts and inter-firm cooperation in Italy. Geneva: International Institute for Labour Studies, 1990.

BRUSCO, S.; SOLINAS, G.- "Partecipazione necessaria e partecipazione possibile", In: L'impresa al plurale. Quaderni della partecipazione, n. 3/4, Milano: Franco Angeli, p. 411-428, 1999.

BRUYNe, P. de; HERMAN, J.; SCHOUTHEETE, M. de. Dinâmica da Pesquisa em Ciências Sociais. Os Pólos da Prática Metodológica. Rio de Janeiro: F.Alves, 1991

CASTELLS, M. Mudança tecnológica: reestruturação econômica e a nova divisão espacial do trabalho. Espaço e Debates, no. 17, ano II, 1986.

CASSIOLATO, J. E; LASTRES, H. M.M. 0 foco em arranjos produtivos e ' inovativos' locais de micro e pequenas empresas.In: LASTRES, H. M. M.; CASSIOLATO, J. E.; MACIEL, M. L. Pequena empresa: cooperação e desenvolvimento local. Rio de Janeiro: Relume Dumará, 2003.

CASSIOLATO, J.E.; SZAPIRO, Marina. Proposição de politicas para a promoção de sistemas produtivos locais de micro, pequenas e médias empresas-Arranjos e sistemas produtivos locais no Brasil. Instituto de Economia da UFRJ, Rio de Janeiro, 2002.

COLEMAN, James S. "Social Capital in the creation of Human Capital". American Journal of Sociology, volume 94 Suplement, 1988, pp. 95-120.

DAGNINO, R.; GOMES, E. Sistema de inovação social para prefeituras. In: CONFERÊNCIA NACIONAL DE CIÊNCIA E TECNOLOGIA PARA INOVAÇÃO. Anais... São Paulo, 2000.

FUKUYAMA, F. Confiança. As virtudes sociais e a criação da prosperidade, Rio de Janeiro: Rocco, 1996.

HUMPHREY, J.; SCHMITZ, H. Governance and upgrading: linking industrial cluster and global value chain researh. IDS Working Paper 120. Institute of Development Studies, UK: University of Sussex, 2000.

IPIRANGA, A. S. R. - Os arranjos e sistemas produtivos locais entre aprendizagem, inovação e cultura. In: XXX ENCONTRO DA ASSOCIAÇÃO NACIONAL DOS PROGRAMAS DE PÓS-GRADUAÇÃO - ENANPAD, 2006, Salvador. Anais... Salvador: ANPAD, 2006.

KRUGMAN, P. Geography and Trade. Cambridge: MIT Press, 1993.

LALKAKA, R. Suporting the Start and Growth of New Enterprises. United Nations Development Programme. Nova York, 1997. 
LE BORGNE, D. La politique industrielle regionale en Italie. Ministère de l'industrie et de l'Aménagement du Territoire/CEPREMAP, Paris, 1991.

MARSHALL, A. Princípios de Economia. São Paulo; Nova Cultural, 1996.

MINISTÉRIO DA CIÊNCIA E TECNOLOGIA-MCT. Manual para implantação de incubadoras. Disponivel em:< www.mct.gov.br/setec.htm $>$ Acesso em: 06.11.2001.

MAGGIONI, M.A.; RICCI,M. Forme alternative di collective learning: um approccio sistemico-popolazionista ed alcune simulazioni" In: CAMAGNI, R.; CAPELLO, R. Apprendimento colletivo e competitività territoriale. Milano: Franco Angeli, 2002.

MESSNER, D.; MEYER-STAMER, J. Governance and Networks. Tools to study the dynamics of clusters and global value chains. Paper prepared for the IDS/INEF Project The Impact of Global and Local Governance on Industrial Upgrading. University of Duisburg, 2000.

PIORE, M.; SABEL, C. The second industrial divide: possibilities for prosperity. New York: Basic Books, 1984.

PYKE, F., BECATITINI, G., SENGENBERGER, W. Industrial districts and inter-firm co-operation in Italy. Geneva: International Institute for Labour Studies, 1992.

PORTER, M. E. Clusters and the new economics of competition. Harvard Business Review, nov-dez, 1998.

PUTNAM, R. Making democracy work: civic traditions in modern Italy. Princeton: Princeton University Press, 1993.

SECRETARIA EXECUTIVA DA REDE DE TECNOLOGIA SOCIAL. Tecnologia social: uma estratégia para o desenvolvimento. Fundação Banco do Brasil - Rio de Janeiro: 2004.

RULLANI, E. "Intelligenza terziaria e reti professionali il nuovo motore dello svluppo" In: Il terziario motore di sviluppo dell'economia. FENDAC, Milano, Giugno 2003.

SAXENIAN, A. Regional Advantage: Culture and Competition in the Silicon Valley and Route 128. Cambridge: Harvard University Press, 1994.

SCHMITZ, H. Collective efficiency: growth path for small-scale industry. Brighton:IDS, 1994 ; Nadvi, Khalid. Clustering and Industrialization: Introduction. World Development, v.27, n.9, pp 1503-1514,1999.

SCOT, A. The geographic foundations of industrial performance. In A. CHANDLER, Jr., HAGSTROM, P.; SOLVELL, O.,(eds.), The Dynamic Firm - The Role of Technology, Organization and Regions. Oxford: Oxford University Press, Chapter 16, 1988.

TENDLER, J.; AMORIM, M. Small Firms and Their Helpers: Lessons on Demand. World Development, Vol.24, No.3: 407-426, 1996.

TENDLER, Judith. Pequenas empresas, o setor informal e o acordo com o diabo. IDS Bulletin [Instituto de Estudos de Desenvolvimento], Vol. 33, No. 3, Julho/2001.

${ }^{1}$ Linda Weiss (1988) (Creating Capitalism: The State and Small Business since 1945) desenvolve esse ponto ao discutir as políticas de desenvolvimento da Itália no pós-guerra.

${ }^{2}$ Ver PIETROBELLI, Carlo. A evolução dos regimes tecnológicos dos distritos industriais: Itália e Taiwan. In: Pequena Empresa Cooperação e Desenvolvimento Local.

${ }^{3}$ Mantivemos os anglicismos porque não nos parece valer a pena cunhar outros termos.

${ }^{4}$ CENTEC (Centro Tecnológico do Ceará) é uma escola pública de ensino superior para a formação de tecnólogos e, em geral, focaliza áreas de conhecimento relacionadas com a vocação da região onde estão instalados. CVT - Centro Vocacional Tecnológico, pertencentes a rede dos CENTECs, mas se dedicam a ministrar cursos de curta duração nas áreas de Matemática e Ciências para professores do ensino médio e fundamental. 